\title{
Capture in the metabolic arena: co-selection of gamma and deltaretrovirus envelope glycoproteins and their receptors
} Marc Sitbon*1, Hiroyuki Abe ${ }^{1}$, Valérie Courgnaud ${ }^{1}$, Donatella Giovannini ${ }^{1}$, Felix Kim ${ }^{1}$, Madakasira Lavanya ${ }^{1}$, Nicolas Manel ${ }^{1}$, Jawida Touhami ${ }^{1}$, Wiliam M Switzer², Pierre Castelnau ${ }^{3}$, Emmanuelle Lagrue ${ }^{3}$, Lydie NadalDesbarats $^{4}$, Karine de Guillen ${ }^{5}$, Christian Roumestand ${ }^{5}$ and Jean-Luc Battini ${ }^{1}$

Address: ${ }^{1}$ Institut de Génétique Moléculaire de Montpellier (IGMM), CNRS-UMR 5535, Université Montpellier 1 et 2, IFR 122, 34293 Montpellier Cedex 5, France, ${ }^{2}$ Centers for Disease Control and Prevention, Atlanta, Georgia, USA, ${ }^{3}$ Service de Neurologie et Neurochirurgie Pédiatrique, Centre de Pédiatrie Gatien-de-Clocheville, CHRU de Tours, 37044 Tours cedex 01 INSERM U930, France, " de Tours, 37032 Tours, France and ${ }^{5}$ Centre de Biochimie Structurale (CBS), UMR UM1/5048 CNRS/554 INSERM, 29 rue de Navacelles, 34090 , Montpellier Cedex, France

* Corresponding author

from Frontiers of Retrovirology: Complex retroviruses, retroelements and their hosts Montpellier, France. 2I-23 September 2009

Published: 24 September 2009

Retrovirology 2009, 6(Supp| 2):120 doi: I0.I |86/1742-4690-6-S2-120

This abstract is available from: http://www.retrovirology.com/content/6/S2/120

(C) 2009 Sitbon et al; licensee BioMed Central Ltd.

Although all infectious and replication-competent retroviruses harbor an env gene, the origin of env remains unknown except for that of a few invertebrate retroviruses. It is generally admitted that infectious retroviruses have evolved from endogenous viral retrotransposons by insertion of an "external" gene that encodes for a fusion glycoprotein (env capture). In 2000, Malik et al. provided the first formal evidence for the origin of env in several invertebrate retroviruses. For instance, they showed that env of Gypsy, an infectious Drosophila retrotransposon, has been "captured" from a fusion protein-encoding gene of a baculovirus, a totally unrelated large DNA enveloped virus.

Vertebrate retroviruses cover 7 genera distinguished by their gag (capsid encoding) and pol (enzyme encoding) genes. The gammaretroviruses (murine leukemia viruses, MLV as a prototype) and deltaretroviruses (the human T cell leukemia virus, HTLV as a prototype) are the most distant genera according to their pol genes. However, we reported that HTLV env is most closely related to MLV env, sharing similar modular organization and motifs even within the receptor-binding domain (RBD), the Env most variable sequence. Accordingly, swapping the RBD-encoding regions between the two types of Env yielded func- tional chimeras. We argued that this common ancestry between the env of remotely related retroviruses is also in favor of an $e n v$ capture scenario by vertebrate retroviruses. Nonetheless, the origin of these env, and more specifically their RBD, remains unknown.

Based on the gammaretrovirus Env modular organization, we derived soluble RBD domains of different gamma and deltaretroviruses. This has been instrumental to the identification of Glut1, the major glucose transporter, as the cognate receptor of HTLV-1 and $2 \mathrm{Env}$. We further showed that Glut1 binds all known HTLV or S(imian)TLV types and that intracellular interaction of HTLV or STLV RBD with Glut 1 modulates glucose transport and glycolysis. Of most interest is that, like Glut1, all of the receptors identified so far for gammaretrovirus Env belong to the family of multimembrane-spanning molecules and that those for which a function has been determined are all metabolite transporters (amino acids, inorganic phosphate, vitamins, etc.).

The selection as Env receptors of metabolite transporters that shuttles from cytoplasmic pools to the cell surface and the cytoplasmic interaction between RBD and their 
cognate receptors have us to postulate that gamma and deltaretrovirus Env, and more particularly their RBD modules, are related to transporter chaperone molecules that modulate their cell surface translocation.

Publish with Bio Med Central and every scientist can read your work free of charge

"BioMed Central will be the most significant development for disseminating the results of biomedical research in our lifetime. " Sir Paul Nurse, Cancer Research UK

Your research papers will be:

- available free of charge to the entire biomedical community

- peer reviewed and published immediately upon acceptance

- cited in PubMed and archived on PubMed Central

- yours - you keep the copyright

Submit your manuscript here:

http://www.biomedcentral.com/info/publishing_adv.asp 